\title{
O momento da tragédia: o papel da educação e da saúde na perspectiva da justiça social
}

The moment of tragedy: the role of education and health in the perspective of social justice

Esse tempo não tem rédea Vem nas asas do vento

O momento da tragédia

Chico Ferreira e Bento

Só souberam na hora do destino apresentar. Gilberto Gil (Parabolicamará)

\author{
Maria Amélia Medeiros Mano ${ }^{1}$ 0000-0003-1260-7515 \\ ${ }^{1}$ Universidade Federal de Ciências da Saúde de Porto Alegre, Departamento de Saúde \\ Coletiva, Porto Alegre, RS, Brasil. Contato: Maria.amelia.mano@gmail.com
}

\author{
Nara Vieira Ramos ${ }^{2}$ 0000-0002-7595-0006 \\ ${ }^{2}$ Universidade Federal de Santa Maria, Centro de Educação, Departamento de Fundamentos \\ da Educação, Santa Maria, RS, Brasil, naravr@terra.com.br
}

Amarildo Luiz Trevisan ${ }^{3}$ 0000-0002-3575-4369

${ }^{3}$ Universidade Federal de Santa Maria, Centro de Educação, Departamento de Fundamentos da Educação, Santa Maria, RS, Brasil, amarildo1.trevisan@gmail.com

Resumo: O artigo aborda um tema ainda pouco debatido no campo da Educação e da Saúde, apesar de todos os avanços das tecnologias da informação e comunicação (TICs), que nos põem em contato com acontecimentos trágicos e catastróficos que ocorrem no mundo a toda hora. O texto parte da análise do "momento da tragédia", questionando o antes e o depois, bem como alguns conceitos em contraste que são caros a essa discussão, como é o caso de natural e humano. A seguir, é feita uma descrição e análise de uma experiência vivenciada, que serve para tensionar alguns conceitos da área de Educação e Saúde. O objetivo é repensar as políticas públicas de Educação e direitos sociais para a formação de uma cultura contra os desastres e para uma percepção dos eventos como construções sociais e humanas. Mais especificamente, defende a ideia de que a redução dos fatores fundamentais de risco deve ser associada à diminuição das desigualdades, cerne das questões de justiça social.

Palavras-chave: Tragédia. Educação. Saúde

Abstract: The article addresses a theme that has not yet been debated in the field of Education and Health, despite all advances in information and communication technologies (ICTs), which bring us into contact with tragic and catastrophic events that occur in the world all the time. The text starts from the analysis of the "moment of the tragedy", questioning the before and after, as well as some concepts in contrast that are expensive to this discussion, as is the case of natural and human. In sequence, a description and analysis of a lived experience is made, which serves to stress some concepts in the area of Education and Health. The objective is to rethink public education policies and social rights for the formation of a culture against disasters and for a perception of events as social and human constructions. More specifically, it supports the idea that the reduction of fundamental risk factors should be associated with the reduction of inequalities, which is the core of social justice issues.

Key words: Tragedy. Education. Health

DOI: http://dx.doi.org/10.1590/S1414-40772019000200013

Este é um artigo publicado em acesso aberto (Open Access) sob a licença Creative Commons Attribution Non-Commercial, que permite uso, distribuição e reprodução em qualquer meio, sem restrições desde que sem fins comerciais e que o trabalho original seja corretamente citado. https://creativecommons.org/licenses/by-nc/4.0/ 


\section{Introdução}

As reflexões deste artigo pretendem se debruçar sobre o papel da Educação e da Saúde nas tragédias na perspectiva dos contrastes: o planejado e o acaso, o que é agudo, visível e choca e o que é crônico, cotidiano, silenciado e banalizado, o que é "humano" e o que é "natural", os desastres próprios da modernidade e a permanência de desigualdades seculares.

Não somente para os processos que desencadeiam, tampouco para os processos que derivam de uma catástrofe, é preciso olhar também para o entremeio das fibras que a compõem, que a mantém, que a fazem ser mais cruel. Entender a dimensão de grandes e pequenos atos banais ou extraordinários, mas, acima de tudo, humanos, é uma perspectiva importante. Tal percepção, juntamente com o fato de que somos parte de uma sociedade que produz iniquidades, nos permite inferir que, em alguma dimensão, somos mais atores do que pensamos. Talvez mais responsáveis do que julgamos ser. Esse é o primeiro passo para uma mudança de direção possível. Esse é o primeiro passo para se pensar em uma educação política e cidadã para a construção de comunidades mais seguras, menos vulneráveis.

O título da música Parabolicamará é a fusão das palavras parabólica, antena eficiente em captar sinais de TV, e camará, palavra-vocativo usada por praticantes de capoeira para se referirem uns aos outros (SILVA, 2010). A música mostra a inversão trazida pela globalização. Se antes o mundo era pequeno e a terra era grande, hoje isso se inverteu graças às infinitas possibilidades de comunicação à longa distância, propiciadas pelas tecnologias de modo geral, em especial as tecnologias da comunicação e informação (TICs). Assim, não só o título, mas toda a música apresenta contrastes não só entre o tradicional e o moderno, mas entre o rural e o urbano, o artesanal e o industrial. Ainda, os tempos: o existencial (psicológico) e o cronológico. As distâncias: longínquas ou próximas, relativizadas pelas diferentes velocidades dos meios de transporte e comunicações - a jangada e o avião citados na música -. A cultura da pequena cidade e a cultura universal. Essas inspirações, bem como o verso posto em epígrafe, traduzem as questões postas nesse artigo.

Para tal reflexão, que de forma alguma pretende abordar ou esgotar todas as faces e todas as contradições aí incluídas, o texto está dividido em três momentos. O primeiro, tal qual a música, e tal qual o título, é "o momento da tragédia". Ou seja, conceitualmente e filosoficamente o que está por trás do fato-momento que chamamos tragédia. O que entendemos por tragédia natural e humana, se é que se pode separá-las. Se é possível também questionar a 
nossa "natureza" e a nossa humanidade enquanto produção de ações como genocídios e extermínios em massa. Há também a descrição da classificação formal e suas insuficiências. É abordado os diferentes entendimentos sobre o uso dos termos: tragédia, catástrofe, desastre e outros tantos (acidente, incidente, ocorrência, etc), estudados em contextos específicos. É claro que não se tem a intenção de aprofundar essa questão conceitual, o que é complexo e fugiria do foco da discussão. Os termos são utilizados respeitando os autores consultados e ainda, o que consagra a literatura sobre o assunto.

A segunda perspectiva traz uma experiência pessoal de um dos autores do artigo no enfrentamento de eventos trágicos. Complementar e menos teórica, tal reflexão mantém a ideia mesma dos contrastes, tal qual a canção. Há, após um evento trágico, uma grande comoção e repercussão coletiva, o que provoca surpresa, estranheza e intenso alvoroço midiático. Mas também, e de maneira especial, há a necessidade de abordar as "pequenas" tragédias que antecedem, permanecem e se sustentam depois que o grande evento sai de cena, enquanto notícia. Existe ainda a necessidade de abordar o que não grita, o que não assusta, o que nem mais é notícia jornalística. Porém, são os silêncios que, na ficção e na vida real, podem marcar mais as pessoas que, como "Chico Ferreira e Bento", da canção de Gil, são surpreendidos pelo que chamam destino e, por essa razão, o subtítulo.

Em tempos de intensas comoções, pouco se discute a história dos atingidos, as vulnerabilidades e, principalmente, as exclusões. Para tal, a partir da Saúde - em particular, a Atenção Primária à Saúde (APS) - e da Educação, é exposto o terceiro momento do texto: lançar olhares e perspectivas dentro do universo da justiça social. A esperança, mais do que a intenção, é de que a partir dessa tentativa de composição, de certa forma complexa, seja possível uma maior percepção da realidade além do que nomeiam destino enquanto determinação e sina. Também urge pensar para além das tragédias, além dos vulcões e tsunamis, das guerras históricas e, em especial, além das guerras sem nome, estas que vitimizam, diariamente, os jovens negros nas favelas brasileiras.

\section{O momento da tragédia}

Conforme a Política Nacional de Defesa Civil (BRASIL, 2000), desastre é uma situação que resulta de eventos adversos sobre um ecossistema vulnerável. Tais eventos, segundo a Política, podem ser naturais ou provocados pelo homem. No entanto, na concepção social, o desastre é um processo que está inserido em uma sociedade que expõe as pessoas às situações de vulnerabilidade. As péssimas condições socioeconômicas, a ocupação inadequada do solo, 
o adensamento urbano em áreas de risco, a falta de investimentos na saúde e na educação, por exemplo, são condições provocadas e, por vezes, mantidas por séculos, submetendo populações inteiras.

Há quem relativize tal ideia, colocando a existência de uma atividade da natureza e, ainda, a noção de intencionalidade. Um bombardeio, por exemplo, é produzido por uma vontade objetiva, ao contrário dos efeitos de um terremoto. Dupuy (2006) entende que tanto quanto um vento forte, o homem que lança a bomba é indiferente à identidade e às características de suas vítimas. Carrascos nazistas, em Auschwitz, eram insensíveis como lavas vulcânicas ao sofrimento de milhares de judeus. De alguma forma, o homem mimetiza a brutalidade cega do tremor de terra. Assim, o homem seria não-humano quando produtor de uma tragédia planejada tanto quanto um vulcão ou um sismo. Ou, de fato, não se pode falar de tragédia natural?

Há duas questões a serem respondidas. A primeira, sobre a humanidade ou a desumanidade do homem frente a atos cruéis. Há que resgatar Rousseau que afirma que "a maior parte dos nossos males físicos é ainda obra nossa" (DUPUY, 2006, p. 1183). No entanto, tradicionalmente, a natureza era entendida enquanto exterior ao mundo humano. Mas, se a natureza se torna, de alguma forma, integralmente o que fazemos dela, pela fabricação e pela transformação, de acordo com os nossos desejos e necessidades, obviamente já se perde o sentido de exterioridade e alteridade. A substituição do feito pelo dado faz parte desse mesmo processo, que, cedo ou tarde, o que fizermos ou não, refletirá nela (DUPUY, 2006).

A segunda questão se refere à existência de tragédia natural. Para compreender melhor é preciso, inicialmente, resgatar a noção de vulnerabilidade e risco. A vulnerabilidade pode ser entendida como a suscetibilidade a perigo ou dano (BRAGA; OLIVEIRA; GIVISIEZ, 2006). Em relação aos "desastres naturais", é a incapacidade de um indivíduo, sociedade ou grupo populacional de evitar o perigo ou ser forçado a viver em condição de perigo (BRAGA; OLIVEIRA; GIVISIEZ, 2006). Já o risco, na perspectiva de desastres, é uma relação matemática que considera o número de mortes em um evento perigoso e a população exposta. Na perspectiva crítica da saúde coletiva, conforme Castiel, Czeresnia e Freitas (2003), é uma forma presente de descrever o futuro sob a premissa de que se pode decidir qual/como deve ser esse futuro desejável, saudável e higiênico. Isso com a justificativa do cuidado e da prevenção da morte prematura, do anseio da velhice saudável.

Porém, mais do que os diversos conceitos sempre imprecisos e relativizados em função de contextos, é possível fazer a relação dos componentes de vulnerabilidade descritos por Cardona (2004) para as questões climáticas, também para as tragédias de uma maneira geral. Assim, de forma abrangente, os três componentes de vulnerabilidade são: a fragilidade 
(componente físico e ambiental), a suscetibilidade (componente socioeconômico e demográfico) e a falta de resiliência (componente comportamental, comunitário e político). É possível, assim, estabelecer uma importante combinação de processos econômicos, políticos, sociais e ambientais, ou seja, quase todos produzidos pelo homem.

Dupuy (2006), sobre a existência de tragédia natural, faz ainda a seguinte reflexão: um risco natural caracteriza-se pela combinação do acaso (fenômeno geológico gerador) com a vulnerabilidade (o efeito sobre os agrupamentos humanos). Em relação ao acaso, puramente, sem a presença humana não há fato. Há realmente muitos sismos em áreas inabitadas que passam somente enquanto registro! Ainda, sobre o acaso, não há controle e o que faz a catástrofe - no plano do seu impacto- é a exposição dos homens. Assim, sendo a vulnerabilidade social uma produção humana que por si só causa dano, uma das conclusões do Decênio Internacional para a Prevenção das Catástrofes Naturais (DIPCN), que terminou em 2000, foi considerar que já não faz mais sentido falar de catástrofe natural: "Se o acaso natural existe, e não o podemos impedir, é a vulnerabilidade social que transforma o fenômeno em catástrofe" (DUPUY, 2006, p. 1183).

Braga, Oliveira e Giviziez (2006) afirmam que entre os indicadores de vulnerabilidade para enchentes, além da exposição, os mais significativos são densidade populacional e PNB per capita. Para os ciclones tropicais, os parâmetros mais significativos foram além da exposição: Índice de Desenvolvimento Humano e percentual de terra arável. O Boletim de Informação sobre Mudança Ambiental Global e Segurança Humana (AVISO, 2005) assevera que variáveis relativas à estrutura familiar também são apontadas também são importantes. Nesse sentido, tanto as famílias chefiadas por mulheres, que são as mais pobres entre os pobres em escala mundial, são aquelas que mais sofrem consequências negativas em desastres diversos por todo o mundo, bem como famílias chefiadas por desempregados ou famílias residentes em moradias subnormais e/ou ilegais.

Assim, é fácil entender porque, estatisticamente, mais de $90 \%$ das mortes por desastres ditos "naturais" em todo o mundo ocorrem nos países mais pobres (LOPES et al., 2010). O terremoto no Haiti, que aconteceu em janeiro de 2010, teve a pontuação de sete na escala Richter e mais de 300 mil mortos, enquanto no Japão, após o terremoto com escala Richter de 8,9, em março de 2011, morreram cerca de 11 mil pessoas. Ainda, um terremoto de 6.5 graus na escala Richter provoca diferentes impactos e números de mortes: cinco óbitos na Califórnia; 20 mil, no Cairo e 40 mil, na Armênia. Assim, a intensidade dos fenômenos depende muito mais do grau de vulnerabilidade do território e das comunidades afetadas do que da magnitude do evento adverso (LOPES et al., 2010). 
Em 2005, o título do editorial do New York Times sobre o Katrina, em Nova Orleans, já admitia que a catástrofe fora causada pelo homem (DUPUY, 2006). Obviamente que não a produção do furacão, mas a evidente exposição cruel das iniquidades da sociedade americana com o desprezo das elites do poder e do dinheiro pelos miseráveis atingidos. Assim, tal qual com o Haiti, a devastação produzida pelo Katrina foi superior e, por esse dano, o homem é o responsável. Uma responsabilidade que também tem a ver com a história de cada território, a forma como foi constituído.

No Brasil, os desastres mais frequentes, sendo pautas repetidas de políticos em campanha, são as enchentes no Sul e Sudeste e as secas no Nordeste. De fato, o Brasil se encontra entre os 20 maiores receptores mundiais de empréstimos para cobrir emergências relacionadas a esses desastres naturais (BRAGA; OLIVEIRA; GIVISIEZ, 2006). Estudos do Banco Mundial e da Universidade de Columbia consideram as regiões Sul, Sudeste e Nordeste com potenciais risco de desastres hidrológicos e de seca (BRAGA; OLIVEIRA; GIVISIEZ, 2006). Fazendo-se uma análise dos últimos 10 anos, no mínimo, constata-se que esses desastres, assim como as epidemias têm um caráter cíclico. Isso nos leva a concluir que os óbitos nessas regiões, provocados pelas tragédias, não podem ser atribuídos somente aos fenômenos naturais como insistem em denominar os responsáveis. Há raízes históricas e sociais profundas. As precárias condições de vida da população e as formas de ocupação do espaço, bem como a falta de acesso aos serviços e equipamentos urbanos, são um problema crônico. Há também e sobretudo um reconhecido descaso governamental pela ausência de políticas que possam prevenir novos eventos ou diminuir o impacto dos mesmos (MANO; BARRETO, 2012).

Recentemente, o Haiti volta a ser notícia com o furacão Matthew (2016), lembrando que o mesmo passou, após, por Cuba, Estados Unidos e República Dominicana. Nos Estados Unidos, inclusive, o furacão ganhou mais intensidade. No entanto, os números ainda não totalmente computados, apontam para uma brutal diferença de mortalidade, bem superior no Haiti frente aos outros países atingidos. Sim, o Haiti está em uma zona de terremotos. Mais que isso, o Haiti é o país mais pobre das Américas e há uma razão histórica. Primeiro, sofreu o genocídio de populações indígenas e a opressão espanhola. Depois, a escravidão dos negros. $\mathrm{O}$ domínio francês veio após para explorar e deixar o país em condição de mais miséria. Livre da França, invasões norte-americanas, ingerências, interferências e ditaduras cruéis assolaram o país. Assim, também a história do Haiti dos últimos 500 anos pode responder pelas tragédias atuais.

Certamente, as duas questões aqui colocadas teriam imensa possibilidade de reflexão e controvérsia. Sobre o que é natural e/ou humano e sobre a humanidade e desumanidade. No 
entanto, não seria possível e nem é objetivo esgotar tais ideias, mas seguir questionando. Para tal, a instigante citação de Dupuy (2006) sobre o termo que acabou por ser usado para descrever o extermínio dos judeus na Europa - shoah - que designa uma catástrofe exclusivamente natural e o termo que os sobreviventes da bomba atômica de Hiroxima e de Nagasáki se referiam à catástrofe - tsunami-. Assim, nos parece que tanto para as atrocidades quanto para os ventos, haverá ações e não ações diretas ou intermediárias, desencadeando processos com desfechos inesperados. Às vezes, não teremos consciência, ao poluir ou desmatar, mas sofreremos todos, em maior ou menor grau, o retorno dos nossos próprios atos.

Com os apoios de Rousseau, Arendt e Günther, Dupuy (2006) entende que o mal é "nosso", somos a fonte do mal, mas tal qual como uma sobrenatureza, este mal transcende-nos. E transcende-nos não só na fabricação de armas mortíferas, mas no orgulho de, com o poder sobre as vidas, definir quem deve viver ou morrer. Tal ideia, bem como a definição de que esse julgamento não é da nossa competência, é uma constatação do físico Robert Oppenheimer, que dirigiu o Projeto Manhattan para o desenvolvimento da bomba atômica na Segunda Guerra Mundial (DUPUY, 2006). Quando Oppenheimer afirma, logo após a explosão em Hiroxima e Nagasáki: "Nós, os físicos, conhecemos o pecado" (DUPUY, 2006, p. 1192), ele fala mais do pecado do orgulho do que do pecado das mortes. A profundidade dessa afirmação, o físico conseguiu esclarecer anos mais tarde. E Dupuy completa:

Penso que a principal ameaça que hoje pesa sobre o futuro da humanidade é a tentação
do orgulho. Sabemos por alto como serão as catástrofes futuras. Aquecimento
climático, destruição do ambiente, tecnologias que escapam ao controle dos que as
conceberam, utilização terrorista ou estatal de armas de destruição em massa, conflitos
mundiais provocados pelo pânico que se apoderará dos povos da Terra quando
tomarem, por fim, consciência de que não a podemos explorar impunemente por
muito tempo: pouco importam ao filósofo as formas particulares que estas catástrofes
tomarão, visto provirem de uma mesma fonte. Em todos os tempos os homens tiveram
de aprender a viver com os resultados inesperados das suas acções, que se viravam
contra eles, como se fossem potências estrangeiras. Desta experiência primordial da
autonomia da acção em relação às intenções dos seus autores nasceram,
provavelmente, o sagrado, a tragédia, a religião a política - outros tantos dispositivos
simbólicos e reais susceptíveis de manterem dentro de limites esta capacidade
altamente perigosa que os homens têm de desencadear, no intrincado dos negócios
humanos, processos irreversíveis e que não têm fim (2006, p. 1192).

Assim, chegamos à ideia de que não há uma simples exposição a um evento perigoso. Há sim, algo historicamente construído por ações humanas e processos sociais. Algo que nos foge, mas nem por isso nos torna menos parte. Algo que retorna para nós e nos faz vítimas tanto quanto nos faz responsáveis. Se conseguimos responder às perguntas, não é tão importante. Importante é perceber o quanto fazemos parte das respostas. 


\section{Classificação}

A globalização e a velocidade das informações nos colocam a par dos principais eventos mundiais quase que em tempo simultâneo. Em 2001, no atentado terrorista de 11 de setembro, em Nova York, segundos separaram a realidade dos aviões se chocando contra as torres gêmeas e a velocidade em que as imagens eram transmitidas para o mundo. Em um outro tempo, víamos o impacto da bomba atômica devastando Hiroxima e Nagasáki. Nessas duas situações, apesar da distância temporal e tecnológica, há uma semelhança: os conflitos têm uma certa clareza e são óbvias as responsabilidades. No entanto, algo mais impreciso se instala quando assistimos à travessia, pelo mar, para a Europa, de milhares de imigrantes fugindo de condições insalubres de vida, guerras, disputas tribais, instabilidades políticas, questões raciais e religiosas e golpes militares. O mesmo ocorre com o homicídio de jovens negros no Brasil. Não há um botão da base nuclear ou um avião terrorista. Qual o nome dessa guerra?

Não é questão fácil de responder pois, certamente, as razões e, portanto, os nomes, para essas guerras sem nome são múltiplas, são antigas e, possivelmente, estão presentes, ainda que silenciosas. Retornamos à ideia da Parabolicamará e os tempos de contrastes. É o estrondo da bomba, os nomes das guerras advindas de processos históricos mais claros. É também o silêncio da sociedade frente a tragédias cotidianas, guerras sem nomes advindas de processos complexos e obscuros. Ainda, para toda grande tragédia, da forma como a entendemos, enquanto fenômeno humano e social, há pequenas tragédias, outros eventos, ditos menores:

Cuando se habla de efectos, hay que considerar no solo los grandes y devastadores eventos ya que, en términos de recurrencia, los eventos menores que usualmente no se cuantifican pueden llegar a sumar daños y perdidas equivalentes a los desastres mayores (CRID, 2009, p. 11).

O que é menor ou maior é uma definição quase impossível. Como parâmetro inicial, há uma classificação tipológica técnica de intensidade dos desastres em quatro níveis, segundo a Política Nacional de Defesa Civil (BRASIL, 2000). No Desastre de Nível I, há pequenas proporções, poucos danos e prejuízos, todos superáveis pela comunidade atingida e com recursos próprios. No Desastre de Nível II, há proporções medianas e prejuízos significativos, mas ainda superáveis por comunidades bem preparadas. A situação de normalidade é restabelecida com recursos locais. No Desastre de Nível III, há grandes proporções e prejuízos. A situação de normalidade é restabelecida não somente com recursos locais, sendo necessária a ajuda estadual e federal. No Desastre de Nível IV, há muita gravidade nas proporções, grandes danos e prejuízos, sem condições de serem superados sem ajuda externa. Por vezes, é necessária a ajuda internacional. 
Ainda, conforme a Política Nacional de Defesa Civil (BRASIL, 2000) também os desastres podem ser súbitos ou de evolução aguda, caracterizados pela velocidade e violência com que ocorrem e pela violência dos eventos adversos (ex.: terremotos). Esses eventos podem ser completamente inesperados (raros) ou sazonais. Os desastres são graduais ou de evolução crônica quando seus efeitos são sustentados e tendem a se agravar e acentuar de forma gradual (ex.: fome e desnutrição). Os desastres por somação de efeitos parciais acontecem quando o grande desastre se define pela somação dos efeitos de pequenos desastres ou acidentes, que ocorrem diuturnamente pelas mesmas causas e com características semelhantes (ex.: grandes epidemias).

É importante entender que nenhuma classificação dá conta completamente da discussão, pois nem sempre leva em consideração os contextos sociais prévios. São tentativas de delimitar situações que nem sempre estão claras porque são processos dinâmicos. O "classificador" se detém, muitas vezes, no recorte do fato, sem o olhar aprofundado. São os referidos contrastes que, para melhor compreensão das dimensões, limitações e aplicabilidades de teorias, vale a descrição da experiência vivida, enquanto modelo e reflexão. Assim, respeitando a classificação didática, será abordado a seguir um desastre agudo vivenciado por um dos autores do artigo. Concomitante, a descrição de um contexto de desastres crônicos e que, se pudesse classificar enquanto intensidade, algo que pouco se faz na nossa realidade contemporânea de banalização do cotidiano, certamente também seria de Nível III a IV. Chamarei propositalmente, no plural, de o(s) desastre(s) por entender que há um evento notadamente trágico, mas há, com ele, o recrudescimento de iniquidades prévias e a construção de outras tantas. O desastre agudo em si, evento de maior visibilidade, foi causado pelas cheias da bacia do Rio Mundaú, em Alagoas.

\section{Chico Ferreira e Bento}

A bacia do Rio Mundaú banha 21 municípios cuja economia é formada basicamente pela agroindústria canavieira, pecuária semi-intensiva, pesca, agricultura, indústria e turismo. Boa parte dessas atividades é de subsistência. Relatos iniciais dos moradores da região indicam que a cheia de 2010 foi a maior da história dessas cidades. Em junho de 2010, havia 26.618 desabrigados e 47.897 desalojados (FRAGOSO JÚNIOR et al., 2010). Foram notificadas 26 mortes e 22 desaparecidos. Branquinha, Santana do Mundaú, União dos Palmares e Quebrângulo foram as mais atingidas, e em Branquinha, 80\% das casas foram destruídas (FRAGOSO JÚNIOR et al., 2010). Vale lembrar que Alagoas é um estado nordestino 
caracterizado pelo latifúndio e a monocultura, com grande concentração de renda, grandes iniquidades e que sofre de abandonos crônicos pelo poder público.

Após o desastre em si, a instituição em que atuo enviou profissionais de saúde para auxiliar as comunidades. Eu compus o grupo que chegou à região após 15 dias do evento, em um período em que várias missões já tinham se retirado - após a situação mais aguda. No entanto, esse é o período em que ocorre a exacerbação de doenças infectocontagiosas somadas, ainda, às questões de saúde mental, ligadas às perdas e ao stress pós-traumático. Havia um Hospital de Campanha (HCAMP) bem equipado que contava com medicamentos, bem como ambulâncias e profissionais de saúde 24 horas. Assim, a estrutura do HCAMP parecia adequada para atender, em local seguro e com boas condições, aos usuários que necessitassem. De fato, apresentava aparelhagem a que poucos já tiveram acesso na região, bem como presença constante de profissionais de saúde, algo também difícil em regiões muito pobres. Não à toa, havia grande aparato midiático em torno do HCAMP.

Enquanto isso, abrigos eram improvisados em escolas e ginásios, muitas vezes distantes do HCAMP e cabe dizer que havia dificuldade de transporte. As diretoras de escolas faziam um trabalho de organização dos abrigos nessas instituições. Pelo número excessivo de pessoas, os ginásios onde funcionavam abrigos eram organizados pelo exército. Havia um contingente maior de pessoal em momentos específicos de provável conflito como, por exemplo, a distribuição de donativos e a hora da alimentação. Nos ginásios, o número elevado de pessoas impossibilitava a organização adequada e o espaço se tornava até mesmo assustador, sobretudo à noite. Cabe dizer que o tempo prolongado de permanência nos abrigos trazia situações de desorganização social e violência.

De fato, os abrigos eram o cenário da degradação humana, principalmente os ginásios. As escolas ainda mantinham uma certa organização. Havia poucos banheiros (cerca de um para cada 150 pessoas em alguns ginásios) e todos em péssimas condições de conservação e higiene. Havia aglomeração (chegamos a contar 57 pessoas dormindo em uma sala de aula), presença de animais, esgoto a céu aberto, acúmulo de água, pouca ventilação o que facilitava a proliferação de doenças. Sob essas condições, muitos atingidos preferiram ficar em suas casas semidestruídas e sem luz, ou mesmo construírem barracas com material alternativo (plástico, papelão, lata, etc). Os que tinham familiares não atingidos, foram acolhidos e muitas casas estavam superlotadas.

Nos abrigos, havia a distribuição de cestas-básicas, colchões, roupas e, ainda, o cadastramento para a construção da nova casa para os desalojados. Assim, pessoas atingidas em outras enchentes, sem teto, pessoas que já viviam em condição de miséria eram atraídas 
para os abrigos, na esperança de saciar a fome e, quem sabe, conseguir uma casa. Quem fazia esse cadastro eram os Agentes Comunitários de Saúde (ACS). Há relatos de que chegaram a sofrer ameaças de pessoas que não eram atingidas por aquela tragédia especificamente, mas que queriam que seus nomes fossem cadastrados. Para piorar, com a enchente, as perdas de culturas e a escassez de hortifrutigranjeiros, o que fazia com que os comerciantes locais aumentassem os valores desses alimentos.

Enquanto havia o movimento para os abrigos de outros sujeitos, as famílias atingidas pouco saíam, não só pela questão dos donativos e cadastros, mas porque havia o risco de furto dos poucos bens que conseguiram recuperar da enchente e que guardavam nos abrigos em espaços improvisados, com divisórias de pano, sem muita segurança. Assim, havia um "esquema de plantão" - casa - abrigo - entre familiares. Esses usuários, por vezes, segundo os ACS, forneciam informações enganosas sobre as perdas, na tentativa de conseguir um pouco mais. Tais pessoas eram vistas como enganadoras e "dificultadoras" do processo. Em função disso, algumas atitudes controversas eram tomadas por "organizadores" como, por exemplo, o "racionamento" de cestas básicas para que, também não houvesse "aproveitamento indevido", "desvio" e até comércio.

No HCAMP havia grande movimentação de políticos e mídia, nos abrigos, havia certa invisibilidade. Algumas empresas visitavam os abrigos, notadamente os de mais fácil acesso. Forneciam donativos (quase sempre acompanhadas de fotos e filmagens) de forma desorganizada, fornecendo inclusive insumos em excesso ou desnecessários para uma região/local, enquanto havia ausência em outros locais. Não era mesmo incomum a venda desses donativos para se obter outros produtos. A desorganização atingia mesmo os profissionais de saúde e redes. Por exemplo, as pastorais e a nutricionista da equipe do Núcleo de Apoio a Saúde da Família, existentes em um município, não tinham visitado os abrigos para avaliar as condições nutricionais das crianças. Médicos locais, de forma burocratizada, insistiam em atender somente pacientes que faziam parte do território em que atuavam, excluindo outros. As consultas eram públicas, rápidas e o alto índice de analfabetismo contribuía para a não compreensão das prescrições.

Em um dado momento de ausência de solução para os desabrigados que permaneciam nas escolas e ginásios, houve um dilema importante. Uma parte significativa das pessoas era beneficiária do Programa Bolsa Família - programa federal destinado às famílias em situação de pobreza extrema - que tem como uma das condicionalidades a frequência escolar. No entanto, com todas as escolas transformadas em abrigos, ocupadas pelas famílias atingidas, as aulas foram suspensas. Apesar de haver justificativa relevante para a ausência das aulas, as 
organizadoras diziam que já não era mais possível sustentar aquela situação e, possivelmente, para retornarem às atividades, transfeririam as famílias das escolas para os ginásios. Os ginásios, que já tinham uma condição de insalubridade e superlotação mais grave que as escolas, corria o risco de se tornarem ainda pior com mais famílias ocupando os espaços.

Algumas poucas famílias foram beneficiadas com o aluguel social - benefício municipal para situações de catástrofes com perda do domicílio. Como em algumas cidades, a destruição foi imensa e, portanto, havia uma redução de moradias viáveis, os proprietários supervalorizavam os aluguéis na tentativa de obterem ganhos. Barracas foram doadas pela Alemanha e, logo que houve uma certa estabilização das famílias, estas foram vendidas para outras famílias desalojadas, o que causou revolta por parte de alguns moradores, dizendo que essas famílias estavam se aproveitando de benefícios. De fato, como já foi mencionado, havia muitos desalojados de outras tragédias e a questão do direito à moradia naquela região é um problema crônico, tanto quanto as cheias.

Nos últimos 100 anos, sete grandes cheias assolaram a região (FRAGOSO JÚNIOR et al., 2010). A cheia de 1969 foi a mais letal para a região, com cerca de 1.100 mortes em pouco mais de quatro horas. Na cidade de São José da Laje, cerca de 400 pessoas morreram. Os corpos foram amontoados na delegacia e causaram grande horror na cidade. A Prefeitura de São José da Laje expediu Decreto Municipal proibindo ocupação por casas na margem do rio, no perímetro urbano da cidade. Isto foi cumprindo com severidade por cerca de dez anos (FRAGOSO JÚNIOR et al., 2010). Em 1990, se finaliza o "Relatório-Diagnóstico sobre os danos causados pelas chuvas de 1988 e 1989”, com sugestões de prevenção contra as enchentes. Nenhuma dessas ações foi executada.

Durante o período de atuação nesses municípios, para mim, a complexidade e a grande tragédia já se instalavam desde muito tempo para aquelas pessoas. Conheci os atingidos da cheia de 1989 ocupando um antigo presídio abandonado. As famílias ocupavam as celas e faziam delas seus lares, quase todos sem banheiro. O condutor da ambulância em que atuávamos disse à equipe, certa vez, que já tinha visto muita tragédia, muitos acidentes violentos com traumas importantes e que, quando envolvem crianças, se tornam mais tristes. No entanto, afirma que o que mais chocava em seu trabalho, sem dúvida, era a pobreza. Disse que já entrou em casas onde o piso era o chorume de um lixão. Havia atendido a urgências em que, na verdade, a vítima tinha fome e conclui: “a diferença é que fome não é um acidente..."

A experiência de Alagoas é um exemplo de que a tragédia se produz e se reproduz tanto quanto as muitas pequenas tragédias de antes e de após. O aumento dos preços dos imóveis e comércio local, a desorganização da gestão, o descomprometimento dos profissionais de saúde, 
a fragilidade das redes, a vulnerabilidade dos territórios e comunidades, a culpabilização dos atingidos, o foco de ações em atividades de visibilidade (HCAMP) em detrimento dos abrigos (com já comprovada demanda 65\% superior em outra situação de tragédia muito semelhante), a falta de estrutura e segurança nos abrigos, de maneira especial para as mulheres e crianças, a reincidência de doenças infecciosas, os atingidos de tantas outras tragédias, de tantos outros tempos. Assim, apesar da invisibilidade perante a mídia que se concentra no caos macro, há um caos micro, produtor de tragédias que persistem e que se somam. Quem arriscará dizer qual a pior das desgraças?

$\mathrm{O}$ ataque terrorista do dia 11 de setembro em 2002 foi impactante e deixou o mundo em alerta. A controversa relação entre Estados Unidos e grupos fundamentalistas islâmicos indica que há uma história de pactos e revides que se repete de forma violenta. No entanto, após o ataque, a barbárie menos visível: a doutrina Bush, que "desde janeiro de 2002 mantém encarcerados na prisão de Guantánamo muitos afegãos e iraquianos, acusados de ligação aos grupos Taliban e Al-Qaeda, sem julgamento algum e em área submetida ao controle internacional" (TREVISAN, 2013, p. 14). Crueldades silenciosas mantém o ódio. Ódio que nasce também da forma com que os imigrantes são tratados em alguns países europeus. Um círculo que se mantém e que, no atual contexto das novas correntes migratórias, tende a produzir novos conflitos, novos ódios e, possivelmente, pequenas e grandes tragédias desde já, anunciadas.

A desgraça histórica de homens brancos buscando fortuna em minas, índios, colonos, negros cativos em trabalho árduo. O trabalho nas minas foi considerado o mais penoso, cruel e pesado desempenhado pelos escravos no Brasil. Risco de morrer pela desnutrição, pelas doenças, pelo tempo na água, no interior das cavernas. Risco de morrer por soterramento. Em 2015, Bento Rodrigues, distrito da cidade mineira histórica de Mariana, conhecida pelas riquezas minerais é o palco da maior catástrofe ambiental mundial ligada a barragens. O que existia antes e o que existe depois da lama tóxica é pouco conhecido. Compreendida como tragédia humana, poderes econômicos e políticos interferem no julgamento, punição e mesmo nas medidas de reconstrução.

Em um outro contexto, sem data, sem números exatos, sem tanto apelo midiático, pessoas vivem debaixo das pontes, crianças iniciam o uso do crack para diminuir a fome e o frio. Desastre crônico de uma sociedade que se impressiona com o desastre agudo dos ataques terroristas. Também não esquecer dos grandes acidentes aéreos e incêndios devastadores, como o da boate Kiss que marcou a cidade de Santa Maria, em 2013. Ambos os desastres: os que convivemos a cada sinaleira com o trabalho infantil e aos que assistimos ciclicamente nos 
telejornais, devem ser passíveis de discussão e aprofundamento. Algo que também deve estar presente na formação de profissionais para o enfrentamento das tragédias da contemporaneidade, com novas situações limite que se somam às antigas e desafiam a compreensão de situações, contextos e saídas.

\section{O destino apresentar}

Destino é sorte, sucessão de fatos necessários e diz respeito à ordem natural estabelecida do universo. É usado para tentar explicar o absurdo dos acontecimentos existenciais tanto quanto responsabilizar divindades. Está muito presente nas tragédias, as individuais, as sociais e, de alguma forma, parece aliviar sofrimento. Assisti a muitos relatos de vítimas de tragédias agudas e crônicas até certo ponto conformadas com o que a vida reservou para elas. Esse parece ser um comportamento muito conveniente para os verdadeiros responsáveis. Porém, se a exclusão social é um destino, a humanidade, e não o divino, é a grande responsável. Se o sofrimento gerado pela miséria é uma sina, são os homens os criadores de tais experiências.

É possível, a partir dos relatos das experiências vividas e das histórias ouvidas, compreender um pouco sobre os processos de exclusão social, descuido de autoridades, inoperância do Estado, desarticulação da rede de atenção, conflitos de interesses e as manobras políticas. Fatores que podem ser tão ou mais trágicos quanto a própria tragédia. A crítica, o enfrentamento de iniquidades, a indignação frente às negligências e injustiças, o incentivo à mobilização e participação popular devem ser pensadas em situações de desastre. Algumas importantes estratégias de enfrentamento nascem também de denúncia, engajamento e comprometimento consciente, racional e preocupado com as pessoas, suas vidas e suas trajetórias de lutas e perdas, sejam elas, agudas ou crônicas, midiáticas ou cruelmente silenciosas.

Segundo relatório do Programa das Nações Unidas para o Desenvolvimento - UNDP (2004), 75\% da população mundial habita em áreas que foram afetadas por tragédias. Há, assim, uma grande possibilidade de estarmos com os pés fincados em uma área de risco. Diversas estatísticas mundiais também afirmam que viver em grandes cidades se traduz em risco, assim, as ruas representam sempre desafios. Há que se perceber e se perguntar, diante do que foi discutido, diante de ameaças e traumas individuais e coletivos, qual é o papel da Saúde e qual o papel da Educação. Na saúde, há ações assistenciais previstas que são complexas e que deveriam ser aprofundadas:

Después de la urgencia de salvar vidas, las acciones siguientes tienen que ver com brindar asistencia oportuna y apropiada a quienes han sufrido daños y pérdidas: 
água segura, saneamiento, salud, alojamiento, alimentación, son algunas de las necessidades que probablemente requerirán ser atendidas en las horas y días posteriores al impacto del evento. Por esa razón, la preparación de la respuesta debe incluir las previsiones para el apoyo temporal a la solución de estas carencias (CRID, 2009, p. 13).

E as referidas ações muito específicas do cuidado em saúde têm uma dimensão fundamental, mas o que se quer discutir nessa reflexão é o contexto que mais a relaciona com a Educação. As Ciências da Educação, conforme Charlot (2006) têm um caráter de imprecisão, há uma opacidade de fronteiras. Também a Saúde e, sobretudo a APS, tem essa característica híbrida. O que é específico da Educação como área de saber é a circulação de diferentes conhecimentos de diferentes origens:

$\& \# 091 ; \ldots \& \# 093$; é um campo de saber fundamentalmente mestiço, em que se cruzam, se interpelam e, por vezes, se fecundam, de um lado, conhecimentos, conceitos e métodos originários de campos disciplinares múltiplos, e, de outro lado, saberes, práticas, fins éticos e políticos (CHARLOT, 2006, p. 9).

Assim, o que define a especificidade da disciplina é essa mestiçagem também presente na APS. A construção do conceito de APS é prévia, mas se consolida nos anos 1980, após a Conferência de Alma-Ata, em 1978. Uma das declarações apresentadas em Alma-Ata descrevia como "inaceitável o estado de saúde de centenas de milhões de pessoas em todo o mundo" (AGUIAR, 2003, p. 43). Segundo o informe oficial, mais da metade da população mundial não recebia assistência à saúde adequada à época do evento (AGUIAR, 2003). No Brasil, a APS adquire caráter especial com a Constituição de 1988, a redemocratização, a reforma sanitária, o nascimento do Sistema Único de Saúde (SUS) e do Programa de Saúde da Família (PSF). O fortalecimento do SUS se dá a partir da APS e PSF - hoje Estratégia de Saúde da Família - e se sustenta teoricamente na definição da Declaração de Alma-Ata:

\begin{abstract}
Atenção Primária à Saúde é a assistência sanitária essencial baseada em métodos e tecnologias práticos, cientificamente fundados e socialmente aceitáveis, acessível a todos os indivíduos e famílias da comunidade, mediante sua plena participação e a um custo que a comunidade e o país possam suportar em todas e em cada uma das etapas de seu desenvolvimento, em um espírito de autorresponsabilidade e autodeterminação. A Atenção Primária é parte integrante tanto do sistema nacional de saúde, do qual constitui a função central e o núcleo principal, como do desenvolvimento social e econômico global da comunidade. Representa o primeiro nível de contato dos indivíduos, da família e da comunidade com o sistema nacional de saúde e leva, na medida do possível, a atenção da saúde aos lugares onde as pessoas vivem e trabalham. Constitui o primeiro elemento de um processo permanente de assistência sanitária (OMS, 1978, p. 3-4).
\end{abstract}

Percebe-se o profundo compromisso social da Saúde em seu conceito ampliado e, por isso, deve estabelecer conexões imprescindíveis com outras ciências. Obviamente que o caráter híbrido e mestiço a que se refere Charlot (2006) em relação à Educação se fortalece também na 
Saúde, a partir desse conceito da Organização Mundial da Saúde. E o que aparentemente fragiliza pela indefinição e fluidez é o que dá o caráter único e profundo, comparando-se com o mundo do conhecimento e porque não dizer, da vida. $\mathrm{O}$ mundo do conhecimento é também fluido com verdades temporárias. Conforme Ferreira, Calvoso e Gonzales (2002, p. 249): “a fluidez do mundo do conhecimento não pode ser superada". E seria prepotência pensar que poderíamos nos debruçar diante de tantos desafios, com tantas certezas.

Sem querer abordar a crise paradigmática em que o conhecimento está mergulhado, vale, diante de problemáticas de tragédias e desastres contemporâneos acreditar em uma prática cotidiana partilhada que invista nos problemas humanos, que não escapam de múltiplas abordagens e incertezas. Assim, os Estados membros das Nações Unidas, no Marco de Ação de Hyogo estabeleceu ações concretas para a redução dos riscos de desastres em cinco áreas fundamentais (CRID, 2009), sendo que todas têm forte conexão com a Educação e com o conceito ampliado de Saúde. As mais relevantes são: criar uma cultura de segurança e resiliência a partir do desenvolvimento de uma maior compreensão e conscientização, usando conhecimento, inovação e educação; reduzir os fatores fundamentais de risco e fortalecer a preparação para uma resposta eficaz aos desastres.

Mais especificamente, a redução dos fatores fundamentais de risco, deve ser associada à redução das desigualdades, cerne das questões de justiça social. Para tal redução, estabelecer a igualdade de oportunidades, oferecendo mais a quem tem menos e entendendo que há sempre a emergência de novas desigualdades, bem como a acumulação de desigualdades "minúsculas" (DUBET, 2014). Sem esse apoio, trabalhadores menos qualificados terão os piores empregos, as piores condições de transporte e saúde, terão dificuldade de acesso ao ócio e à alegria, terão menos qualidade de vida (DUBET, 2014).

Políticas públicas devem garantir Educação e direitos sociais para a formação de uma cultura contra os desastres e para uma percepção dos eventos como construções sociais, humanas. Pesquisas devem ter uma aplicação prática e ética dos conhecimentos que precisam ser contextualizados "tanto pelos meios como pelos fins, daí decorrendo dever o cientista falar como cientista e cidadão, simultaneamente, no mesmo discurso" (FERREIRA; CALVOSO; GONZALES, 2002, p. 248). Nesse sentido, o critério fundamental para se validar o conhecimento, em uma visão mais pragmática, passa a contemplar o quanto o conhecimento desenvolvido pode trazer "uma maior compreensão e benefícios para o ser humano, tanto em termos individuais, quanto sociais, portanto sendo privilegiado um critério ético de relevância" (FERREIRA; CALVOSO; GONZALES, 2002, p. 249). 
Como exemplo de pesquisa em que a temática dos desastres é central, tem-se o projeto desenvolvido na Universidade Federal de Santa Maria (Rio Grande do Sul) a partir da tragédia da boate Kiss, cujo incêndio vitimou 242 pessoas, na maioria jovens (TREVISAN, 2013). A intenção, além de auscultar as modificações ocorridas no cotidiano da educação da cidade de Santa Maria, era propor um modelo de formação sensível à prevenção das catástrofes coletivas (TREVISAN, 2013). Catástrofe, trauma e resistência são temas que emergem da experiência empírica e do legado teórico acumulado. A proposta, na perspectiva da filosofia da educação, parte de intervenções estéticas e sensíveis com educadores que tiveram contato com as vítimas. A intenção é permitir uma abertura a novas visões de mundo, com as palavras, com os silêncios, com as utopias necessárias para que as tragédias não se repitam.

Enquanto exemplo de experiência, cita-se a do município de Olinda realizada em 2006. Com o objetivo de aumentar a resiliência das comunidades no enfrentamento dos desastres, cerca de 20 jovens participaram de um curso realizado aos finais de semana, na escola municipal, para identificar pontos de risco e colaborar nas ações para prevenção de desastres nos morros. Após o término do curso, os alunos concluintes atuaram no $1^{\circ}$ Núcleo Comunitário de Defesa Civil Jovem (NUDEC Jovem) de Olinda, que funciona na própria escola. Junto com o treinamento, os jovens participaram de um curso de teatro e discutiram a história ocupacional do território, aprendendo formas de preservar o meio ambiente e evitar deslizamento de barreiras e alagamentos (MANO; BARRETO, 2012).

Os dois exemplos relatados são diversos em termos de contexto e atuação. O primeiro, age sobre o depois, buscando subsídios para a compreensão e para a prevenção a partir da Educação. O segundo, age sobre o antes e também traz uma forte relação com a Educação. Outro ponto em comum é a necessidade de incluir a arte e a leveza em um tema que por si só gera dor. Tal característica se faz relevante para todos os grandes problemas que atingem o homem. A forma com que uma questão impactante é apresentada pode gerar fuga, pode gerar aproximação que, geralmente, se faz pela identificação, pelo sensível, pela arte. E pela arte, outra área mestiça, como a Educação e a APS, há comoção e movimento. Não ao acaso, esse artigo fala sobre tragédias a partir dos versos de uma canção.

\section{Conclusões}


$\mathrm{O}$ artigo buscou estruturar a relação entre desastre, risco, desigualdade social com educação e saúde, defendendo o ponto de vista de que o motor da desigualdade social se dá pela ausência de operacionalização do sistema de proteção social, aqui representado pela saúde e educação públicas, objeto da presença estatal na sociedade. O surgimento de amplos sistemas de proteção social no Brasil e na América Latina ocorreram não como um direito universal, inerente à condição da cidadania, e sim como moeda de troca para consolidar o exercício do poder que mantém e perpetua as desigualdades sociais.

Por isso, após os relatos de algumas experiências de enfrentamentos de desastres e tragédias há que se retornar à música Parabolicamará, de Gilberto Gil, aos contrastes de tempos, tecnologias e possibilidades anunciados no início. No entanto, há que se reconhecer que há contrastes, diferenças, também em relação ao acesso a essas tecnologias que encurtam tempos, que facilitam e que, por vezes, permitem a vida. Há contrastes no acesso à produção e distribuição do conhecimento, algo que aparece, na canção, no momento da tragédia, quando Chico Ferreira e Bento, sujeitos do mundo, da vida, só souberam na hora em que o destino apresentou. E não está claro se o destino apresentou a tragédia enquanto surpresa ou o destino é tão somente essa trajetória de pequenas grandes desgraças de tempos atuais e antigos.

Diante do explicitado, falar de tragédias naturais é reduzir a dimensão de causas, fatos e consequências. Perceber uma ameaça natural somente não é o suficiente (CRID, 2009). Concordando com Mayer, Dubet vai referir ainda que pode não ser suficiente abordar as desigualdades a partir de programas sociais que têm o seu papel, mas tornam o sujeito cliente e devedor antes que seja ator e autor na/da sociedade (DUBET, 2014). Construir comunidades seguras a partir de um projeto que combine proteção do meio ambiente, construção de redes, mobilização social e, a redução das iniquidades é importante. Ainda, cabe abordar e combater a discriminação que se assenta sobre estereótipos negativos (DUBET, 2014) que costumam culpabilizar e criminalizar a vítima, tal qual ocorreu na experiência relatada nas cheias em Alagoas e tal qual acontece no cotidiano, em diversas situações.

A associação entre elementos como crime organizado, violência e pobreza conduzem as políticas sociais a funções retrógradas de apaziguamento e baixa capacidade de promover equidade. A tendência declinante da atenção primária à saúde e educação impelem determinados grupos sociais em direção à discriminação e à miséria, reforçando as vulnerabilidades e as enfermidades. O estado como ator social e democrático não pode permanecer à margem ou ausente da rede de proteção social, pois se as desigualdades, as negligências, os silêncios perante as injustiças, as pestes agudas (parte delas emergentes de desequilíbrios ecológicos e condições de vida) e os males crônicos (parte deles resultado de 
hábitos de vida) tanto quanto as guerras são processos e construções, há que se reconhecer responsabilidades diretas e indiretas, grandes e pequenas. Com essa perspectiva, não há determinação ou destino, mas a possibilidade de assumir as rédeas e construir saídas viáveis, mesmo que temporárias. Os atributos da APS e as características de processos educacionais, notadamente a Educação para a Justiça Social fazem parte de um caminho possível de ser trilhado.

No entanto, seria uma ingenuidade a luta pela redução de iniquidades sem resistências. É importante estar atento a discursos que defendem a prevenção, a educação e o incentivo a APS sob paradigmas paternalistas e instrumentais, que podem não modificar realidades. As ações preventivas são mais econômicas, mas o fato de evitarem sofrimento e morte é o mais importante. Ainda, frequentemente, há que se ter um aporte financeiro para o incremento se ações preventivas que nem sempre apresentam resultados imediatos. A conscientização da comunidade pode evitar a submissão e a dependência o que nem sempre é o suficiente. O incentivo ao empoderamento e à autonomia deve ser mais eficaz, pois a sensibilização e percepção dos riscos fortalece os enfrentamentos. No entanto, a percepção das iniquidades enquanto risco pode ser mais relevante na luta por melhores condições de vida.

Concluindo, sobre a aproximação entre os discursos e práticas é importante dar sempre um passo à frente. Também, muitas vezes, na incompreensão de processos velados, caóticos e atravessados por poderes e interesses múltiplos, é desejável dar um passo atrás para entender o contexto, antes de julgar ou agir. Vale a redução de impactos e mitigação de respostas quando é o único caminho em um tempo-lugar. Mas vale a luta humana, contra esse mesmo humano que produz injustiças, a luta contra as iniquidades, pela garantia do direito de escolher onde morar, onde viver. Escolha que quando retirada de indivíduos e comunidades pode ser, em si, a maior tragédia.

\section{Referências}

AGUIAR, Raphael Augusto Teixeira de. A construção internacional do conceito de atenção primária à saúde (APS) e sua influência na emergência e consolidação do sistema único de saúde no Brasil. 2003. Dissertação (Mestrado em Saúde Pública) Faculdade de Medicina, Universidade Federal de Minas Gerais, Belo Horizonte, 2003. Disponível: http://www.bibliotecadigital.ufmg.br/dspace/bitstream/handle/1843/ECJS76RHW7/raphael_augusto_teixeira_de_aguiar.pdf?sequence=1. Acesso em: 24 jun. 2018.

AVISO. Information Bulletin on Global Environmental Change and Human Security, n. 14, oct. 2005. Disponível em:

http://www.ihdp.unu.edu/docs/Publications/GECHS/Aviso/Aviso14-2005.pdf. Acesso: 24 jun. 2018. 
BRAGA, Tania Moreira; OLIVEIRA, Elzira Lúcia de; GIVISIEZ, Gustavo Henrique Naves. Avaliação de metodologias de mensuração de risco e vulnerabilidade social a desastres naturais associados à mudança climática. São Paulo em Perspectiva, São Paulo, v. 20, n. 1, p. 81-95, jan./mar. 2006.

BRASIL. Ministério da Integração Nacional. Secretaria de Defesa Civil. Política Nacional de Defesa Civil. Brasília-DF, 2000. Disponível em:

http://www.defesacivil.mg.gov.br/images/documentos/Defesa\%20Civil/manuais/Pol\%C3\%A Dtica-Nacional-de-Defesa-Civil.pdf. Acesso em: 24 out. 2018.

CARDONA, Omar. The need for rethinking the concepts of vulnerability and risk from a holistic perspective: a necessary review and criticism for effective risk management. In: BANKOFF, Greg; FRERKS, Georg; HILHORST, Dorothea (eds.). Mapping vulnerability: disasters, development, and people. London: Earthscan Publications, 2004. p. 37-51.

CASTIEL, Luís David; CZERESNIA, Dina; FREITAS, Carlos Machado de. Dédalo e os Dédalos: identidade cultural, subjetividade e os riscos à saúde. In: CZERESNIA, Dina; FREITAS, Carlos Machado de. Promoção da saúde: conceitos, reflexões e tendências. Rio de Janeiro: Fiocruz, 2003. p. 79-95.

CRID - Centro Regional de Información sobre Desastres para América Latina y el Caribe. Catálogo de herramientas y recursos de información para el Fortalecimiento de Capacidades Locales de Respuesta. Centro Regional de Información sobre Desastres para América Latina. San José, CR: CRID, 2009.

CHARLOT, Bernard. A pesquisa educacional entre conhecimentos, políticas e práticas: especificidades e desafios de uma área de saber. Revista Brasileira de Educação, Rio de Janeiro, v. 11, n. 31 jan./abr. 2006.

DUBET, François. Repensar la justicia social: contra el mito de la desigualdade de oportunidades. Buenos Aires: Siglo Veinteiuno, 2014.

DUPUY, Jean-Pierre. Ainda há catástrofes naturais? Análise Social, Lisboa, v. 41, n. 181, p. 1181-1193, 2006. Disponível em:

http://analisesocial.ics.ul.pt/documentos/1218723769F0xBP0ve1Lf54HP1.pdf. Acesso em: 25 out. 2018.

FERREIRA, Ricardo F.; CALVOSO, Genilda G.; GONZALES, Carlos B L. Caminhos da pesquisa e a contemporaneidade. Psicologia: Reflexão e Crítica, Porto Alegre, v. 15, n. 2, p. 243-250, 2002.

FRAGOSO JÚNIOR, Carlos Ruberto et al. Reflexões sobre a cheia de junho de 2010 nas Bacias do Rio Mundaú e Paraíba. Maceió: UFAL, 2010. Disponível em: http://www.ctec.ufal.br/professor/vap/Cheia2010.pdf. Acesso em: 25 out. 2018.

GIL, Gilberto. Parabolicamará. Intérprete: Gilberto Gil. Gilberto Gil Unplugged. [S.1]: Warner Music, p. 1994. 1 CD. Faixa 10. 
LOPES, Daniela da Cunha et al. Gestão de riscos e de desastres: contribuições da psicologia. Centro Universitário de Estudos e Pesquisas sobre Desastres. Florianópolis: CEPED/UFSC/Associação Cultural Cabeça ao Vento, 2010.

MANO, Maria A. M.; BARRETO, Danyella. Tragédias. In: GUSSO, Gustavo; LOPES, José Mauro Ceratti (org.). Tratado de medicina de família e comunidade: princípios, formação e prática. Porto Alegre: ArtMed, 2012. p. 459-468.

OMS - Organización Mundial de la Salud. Atención primaria de salud: informe de la conferencia internacional sobre atención primaria de salud. Ginebra: OMS, 1978. Disponível em: http://apps.who.int/medicinedocs/documents/s21370es/s21370es.pdf. Acesso em: 25 out. 2018.

SILVA, Beatriz Pereira. Ciência e vida moderna na dialética musical de Gilberto Gil. Cadernos do CNLF, Rio de Janeiro, v. 14, n. 2, t. 1, p. 705-740, 2010.

TREVISAN, Amarildo Luiz. Catástrofe, trauma e resistência: experiência estética na formação de professores. Projeto de Pesquisa. Edital Universal - CNPq - Faixa B, 2013.

UNDP. Reducing disaster risk: a challenge for development, a global report. UNDP Bureau for Crisis Prevention and Recovery. New York: UNDP, 2004. 